\title{
Inhibition of Nitric Oxide Synthase Enhances Cocaine's Developmental Toxicity: Vascular and CNS Effects
}

\author{
Mary Irene Mendoza-Baumgart', Marco Pravetoni' and Sheldon B Sparber*, \\ 'Department of Pharmacology, University of Minnesota, Minneapolis, MN, USA; ${ }^{2}$ Department of Neuroscience, University of Minnesota, \\ Minneapolis, MN, USA
}

\begin{abstract}
Ischemia and/or reperfusion injury from free radicals may cause cocaine's toxicity, including its effect upon neurobehavioral development. We previously used salicylate to measure hydroxyl free radicals in chick embryos exposed to cocaine. The combination was more toxic than cocaine alone. We postulated that salicylate enhanced the vasoconstriction and toxicity via inhibition of compensatory processes (eg by inhibition of the synthesis of vasodilatory prostanoids and/or nitric oxide). A nontoxic dose of N(G)-nitro-L-arginine methyl ester (L-NAME) was used to inhibit nitric oxide synthase to test this hypothesis. In one experiment, cocaine was injected every I.5 h (total dose $=67.5 \mathrm{mg} / \mathrm{kg}$ egg) on day I 5 of development, I h after injection of L-NAME (200 mg/kg egg) to determine viability and hatchability, which are measures of toxicity. Another experiment measured diameters of blood vessels after L-NAME injection, followed by $\mathrm{NaCl}$ or cocaine infusion $(0.23 \mathrm{mg} / \mathrm{egg} / \mathrm{min}$; total dose $=67.5 \mathrm{mg} / \mathrm{kg}$ egg $)$ at 15 and $5 \mathrm{~min}$ afterwards. Lastly, brains of embryos pretreated with L-NAME before cocaine injections were analyzed for nitric oxide synthase activity. Cocaine decreased viability and hatchability. L-NAME enhanced cocaine's effect upon both parameters. Blood vessel diameters were decreased by cocaine after I 5 min of infusion. L-NAME + cocaine caused a decrease in vessel diameter as soon as 5 min into the infusion and was greater with time, compared with other groups. Enzyme activity in brains was decreased only in the L-NAME + cocaine group. Thus, inhibition of nitric oxide synthesis interferes with the embryos' capacity to mount a compensatory vasodilatory response.

Neuropsychopharmacology (2007) 32, 940-945. doi:I 0. I038/sj.npp. I 30 I I 57; published online 26 July 2006
\end{abstract}

Keywords: cocaine; L-NAME; blood vessel; chick embryo; nitric oxide; brain

\section{INTRODUCTION}

Human and animal studies have reported cerebrovascular accidents (ie hemorrhage and/or ischemia) in adults, as well as in offspring of cocaine-using mothers (Levine et al, 1991; Frank et al, 1999; Kapur et al, 1991; Akoka et al, 1999). In utero, exposure to cocaine has been shown to cause various detrimental consequences including, but not limited to congenital malformations and postnatal neurobehavioral changes (Young et al, 1992; Plessinger and Woods, 1993; Vorhees et al, 1995).

When sodium salicylate was injected into chicken eggs with embryos to determine if cocaine's developmental toxicity might be due, in part, to elevated free radical production, we observed evidence of enhanced toxicity in E18 embryos caused by the combination (Castelli et al, 2001). We also reported that salicylate, in combination

* Correspondence: Dr SB Sparber, Department of Pharmacology, University of Minnesota, 6-120 Jackson Hall, 321 Church St., SE, Minneapolis, MN 55455-02 17, USA, Tel: + I 612625 5657, Fax: + I 612625 8408, E-mail: sparb00।@umn.edu

Received 13 December 2005; revised 6 June 2006; accepted 8 June 2006

Online publication: 12 June 2006 at http://www.acnp.org/citations/ Npp06 1206050739/default.pdf with cocaine, can exacerbate cocaine's toxic effect upon younger (ie E12) chicken embryos, manifest as hemorrhages and reduced hatchability in the presence of hydroxyl free radicals (Venturini and Sparber, 2001). Recently, we demonstrated that salicylate enhanced the vasoconstrictive effect of cocaine and that the degree of vasoconstriction was inversely related to embryonic brain-inducible nitric oxide synthase mRNA concentration (Mendoza-Baumgart et al, 2004). We hypothesized that this enhanced vascular and other toxic effects of cocaine by salicylate was owing to the blockade of compensatory mechanisms, such as production of prostacylin and/or nitric oxide, which are both powerful vasodilators (Shimokawa et al, 1988; Vane and Botting, 1998; Ignarro, 2002). In addition to its effect upon prostanoid synthesis, salicylate has been reported to decrease nitric oxide formation by interfering with the post-transcriptional, translational, and post-translational processing of nitric oxide synthase (Amin et al, 1995; Ryu et al, 2000). We proposed that the increase in brain synthase mRNA caused by the combination of salicylate + cocaine may have been the result of a positive feedback in an effort to compensate for, or counteract the decrease in the synthesis of nitric oxide in the periphery or brain. The present study was carried out to determine the consequence of direct 
synthase inhibition, with and without cocaine, upon viability, hatchability (ie toxicity), extraembryonic blood vessel diameters, as a parameter of vascular function, and to determine the effect of synthase inhibition, with and without cocaine, upon chick embryo brain enzymatic activity. To test the hypothesis discussed above, essentially the same treatment protocols used in the salicylate experiments were used for these experiments. Nontoxic doses of salicylate were used as a reactant to 'trap' any hydroxyl free radicals generated as a result of ischemia and reperfusion. These experiments were carried out to determine if cocaine's developmental effects were also enhanced by pretreatment with a nontoxic dose of $N(G)$-nitro-L-arginine methyl ester (L-NAME) in order to inhibit nitric oxide synthase enzymatic activity directly.

\section{METHODS}

\section{Subjects}

Fertilized chicken (Gallus domesticus) eggs (White Leghorn $\times$ White Leghorn) were obtained from Midwest Poultry and Hatchery (Dassel, MN). The eggs were stored overnight at $14-16^{\circ} \mathrm{C}$ to synchronize embryo development. They were then set in a rotating forced air incubator/ hatcher (Humidaire, New Madison, $\mathrm{OH}$ ) with the temperature set at $37.5^{\circ} \mathrm{C}$ and the relative humidity at $58-60 \%$. The day eggs were placed in the incubator was designated as embryonic day 0 (E0). On E14, the day before injection/ infusion of drugs, the eggs were candled and treatment was assigned randomly to eggs with viable embryos. An injection site for drug administration was marked about $2.0 \mathrm{~cm}$ below the air cell, avoiding membrane-bound blood vessels that could be observed during the candling procedure. The shell surface at the injection site was sterilized with a small drop of $2 \%$ iodine tincture and immediately wiped off with a gauze pad moistened with $70 \%$ ethanol. A 1.2-mm diameter dental burr and a small drill were used to drill injection holes without puncturing the underlying membrane. Holes were covered with a small piece of transparent plastic tape (3 M, St Paul, MN).

\section{Drugs}

Cocaine $\mathrm{HCl}$ was kindly provided by the National Institute on Drug Abuse. L-NAME was purchased from Sigma (St Louis, MO). All drugs were dissolved in filtered (Acrodisc $0.2 \mu \mathrm{m}$ filter, Pall Corp, Ann Arbor, MI) distilled water just before their use. The dose of cocaine, as the $\mathrm{HCl}$ salt, was based on previous experiments in our laboratory, within the range that produces moderate to severe effects, including reduced hatchability of chick embryos. Based on our preliminary toxicity studies, the L-NAME dose used was devoid of toxicity (ie reduced hatchability) when administered alone. Avian isotonic $\mathrm{NaCl}(0.85 \%(\mathrm{w} / \mathrm{v})$ was used for control injections and infusions.

\section{Protocols}

See Figure 1a-c for a visual description of the separate experimental protocols.
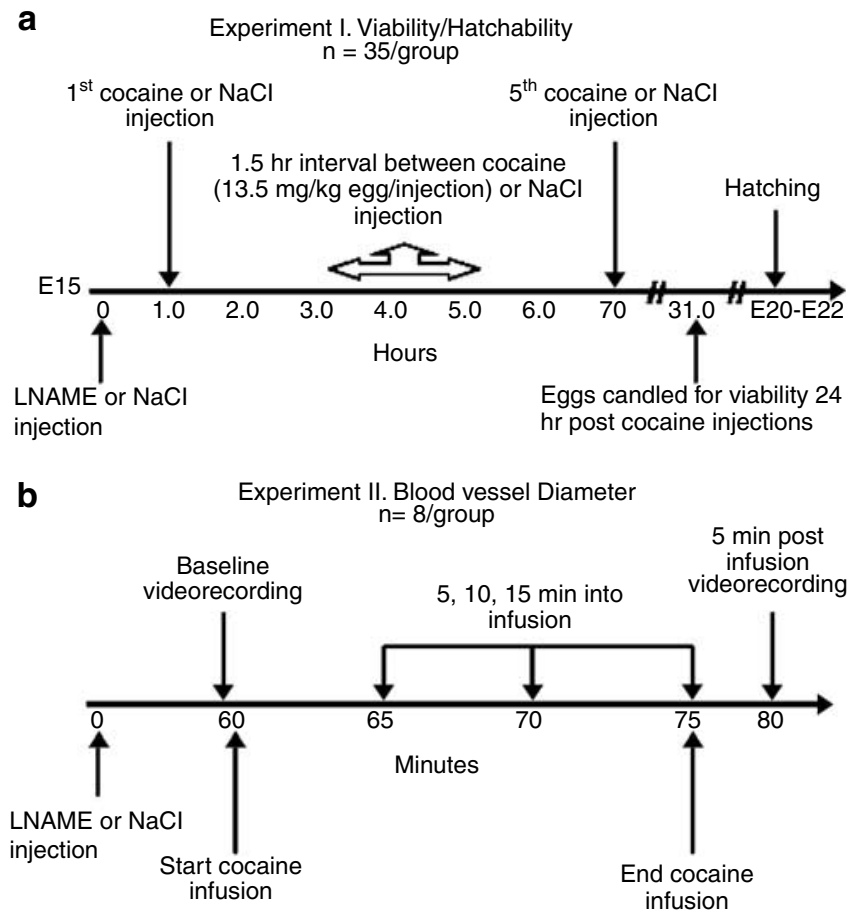

C Experiment III. Brain Isolation and Nitric Oxide Synthase Activity

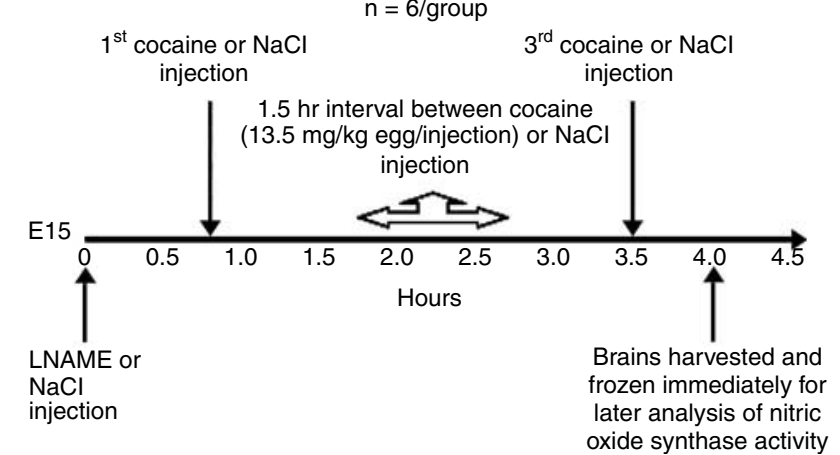

Figure I Experimental design. (a) The viability and hatchability experiment; (b) the blood vessel experiment; and (c) the brain isolation and nitric oxide synthase activity experiment.

Viability and hatchability. On E15, 35 eggs per treatment group were injected with L-NAME $(200 \mathrm{mg} / \mathrm{kg}$ egg or $10 \mathrm{mg} /$ egg) or $\mathrm{NaCl} 1 \mathrm{~h}$ before five injections of $13.5 \mathrm{mg}$ cocaine $/ \mathrm{kg}$ egg (average egg weight $=50 \mathrm{~g}$; total dose of $67.5 \mathrm{mg} / \mathrm{kg}$ egg) or $\mathrm{NaCl}$. Volume of injection was $20 \mu \mathrm{l}$ and injections were administered at $1.5 \mathrm{~h}$ intervals. We have used this injection protocol in the past as a 'model' of embryonic/fetal exposure as a consequence of binge cocaine use by pregnant women (Castelli et al, 2001; Schrott and Sparber, 2001; Venturini and Sparber, 2001). After $24 \mathrm{~h}$, eggs were candled for viability and were then returned to the incubator. On E18, eggs were transferred to the hatcher compartment, which was checked three times daily for new hatchlings, starting on E20 until E22. Treatment groups are as follows: $\mathrm{NaCl}+\mathrm{NaCl}, \mathrm{NaCl}+$ cocaine, L-NAME $+\mathrm{NaCl}$, and L-NAME + cocaine (Figure 1a).

Blood vessel diameter. On E15, eggs were injected with L-NAME $(200 \mathrm{mg} / \mathrm{kg}$ egg) or $\mathrm{NaCl}$ followed $1 \mathrm{~h}$ later by 
infusion of $\mathrm{NaCl}$ or cocaine $(67.5 \mathrm{mg} / \mathrm{kg}$ egg; $0.225 \mathrm{mg} / \mathrm{egg} /$ min) during $15 \mathrm{~min}$. Treatment groups ( $n=8$ /group) consisted of: $\mathrm{NaCl}+\mathrm{NaCl}, \mathrm{NaCl}+$ cocaine, L-NAME $+\mathrm{NaCl}$, and L-NAME + cocaine. The procedure and equipment used are described in detail elsewhere (Zhang et al, 1998; Mendoza-Baumgart et al, 2004). Briefly, the eggshell above the aircell was removed and the chorioallantoic membrane was made transparent with a drop of mineral oil so as to visualize, record, and measure the apparent diameter of extraembryonic vitelline blood vessels before, during, and after infusion of $\mathrm{NaCl}$ or cocaine in eggs previously injected with $\mathrm{NaCl}$ or L-NAME. A $1 \mathrm{~cm}$ long, 250-mm-diameter, 3.0 silk suture, previously soaked in mineral oil, was placed near the desired blood vessel as a reference (Figure $1 \mathrm{~b}$ ).

Brain isolation and nitric oxide synthase activity. Thirty minutes after the third injection of cocaine (ie after $40.5 \mathrm{mg}$ cocaine $/ \mathrm{kg}$ egg) or $\mathrm{NaCl}$, whole embryo brains were rapidly externalized and immediately frozen in liquid nitrogen and stored at $-80^{\circ} \mathrm{C}$ (Figure 1c). We took brains after the third injection instead of after five injections because we had observed L-NAME-enhanced vasoconstriction after acute infusions of $22.5-45 \mathrm{mg}$ cocaine $/ \mathrm{kg}$ egg, at times when cocaine did not yet cause significant vasoconstriction (ie within 5-10 min after starting cocaine infusions). Thus, we wanted to determine if L-NAME + cocaine caused a greater reduction in enzyme activity after a dose of cocaine comparable to that which caused significant vasoconstriction, before the vasoconstriction caused by cocaine itself was manifest. Brains were thawed in two volumes (weight of tissue/volume of buffer) of ice-cold homogenization buffer composed as $25 \mathrm{mM}$ Tris- $\mathrm{HCl}$ ( $\mathrm{pH} 7.4), 1 \mathrm{mM}$ ethylenediaminetetraacetic acid (EDTA), and $1 \mathrm{mM}$ ethyleneglycolbis(-aminoethylether)- $N, N, N^{\prime}, N^{\prime}$-tetraacetic acid, all reagents purchased from Sigma (St Louis, MO). Brains were homogenized using a tissue homogenizer (STD1810; Tekmar, Cincinnati, $\mathrm{OH}$ ) and homogenates were centrifuged at $20000 \mathrm{~g}$ for $15 \mathrm{~min}$ at $4^{\circ} \mathrm{C}$ using a refrigerated centrifuge (J2-21 Beckman, Fullerton, CA). After centrifugation, supernatants were transferred to fresh $1.5 \mathrm{ml}$ Eppendorf tubes and kept on ice until incubation (Figure 1c).

Measurement of nitric oxide synthase catalytic activity is based upon conversion of arginine into citrulline during the production of nitric oxide. The method of Bredt and Snyder (1990), with modifications for optimizing use with embryonic chicken brain, was used. Reaction mixtures were prepared on ice as follows: $25 \mathrm{mM}$ Tris- $\mathrm{HCl}$ ( $\mathrm{pH} 7.4$ ), $3 \mu \mathrm{M}$ tetrahydrobiopterin, $1 \mu \mathrm{M}$ flavin adenine dinucleotide, $1 \mu \mathrm{M}$ flavin adenine mononucleotide, $0.1 \mathrm{mM}$ nicotinamide adenine dinucleotide phosphate, reduced form (NADPH), $1 \mathrm{mM}$ calcium chloride, and $1 \mathrm{mM}$ magnesium diacetate (Sigma). In $1.5 \mathrm{ml}$ microcentrifuge tubes, $40 \mu \mathrm{l}$ of brain homogenates were added to $40 \mu \mathrm{l}$ of reaction mixture and samples were incubated for $10 \mathrm{~min}$ at $30^{\circ} \mathrm{C}$ in a Dubnoff shaking metabolic incubator (Precision Scientific, Chicago, IL) to warm the mixture and convert any residual endogenous arginine to citrulline. Radiolabeled substrate was then added to samples. Arginine substrate $(0.5 \mathrm{mM})$ was composed of $0.5 \mu \mathrm{M} \mathrm{L}-\left[2,3,4,5-{ }^{3} \mathrm{H}\right]$-arginine $(62.0 \mathrm{Ci} /$ $\mathrm{mM}$; Amersham, Little Chalfont, UK) and $499.5 \mu \mathrm{M}$ L-arginine (Sigma). Reactions were stopped after $30 \mathrm{~min}$ by adding $450 \mu \mathrm{l}$ of stop buffer composed as $50 \mathrm{mM} \mathrm{N-2-}$ hydroxyethylpiperazine- $N^{\prime}$-2-ethanesulfonic acid (HEPES) at $\mathrm{pH} 5.5$ and $5 \mathrm{mM}$ EDTA. After incubation, a fraction $(540 \mu \mathrm{l})$ of the final volume (reaction mixture, homogenate, and stop buffer) was transferred to microspin nylon-filter tubes (Alltech, Deerfield, IL) containing $160 \mathrm{mg}$ of AG 50WX8 Resin, 100-200 mesh, and sodium form (Biorad, Hercules, CA). Samples were briefly stirred in the spin cups in order to maximize the exposure to the cation exchange resin and then centrifuged at $3000 \mathrm{~g}$ for $3 \mathrm{~min}$ at room temperature. The cation exchange resin traps ${ }^{3} \mathrm{H}$ arginine, whereas ${ }^{3} \mathrm{H}$-citrulline, stoichiometrically $(1: 1)$ formed during the production of nitric oxide, is collected in the flowthrough after centrifugation. A fraction $(450 \mu \mathrm{l})$ collected from column holders was transferred to scintillation vials (RPI, Mt Prospect, IL) and $1.5 \mathrm{ml}$ of scintillation fluid (Ecolume, ICN, Costa Mesa, CA) was added. After $24 \mathrm{~h}$ of dark adaptation, sample radioactivity was quantified in a liquid scintillation counter (LS 5801 Beckman, Fullerton, CA). Counter error was preset at $2 \sigma$ or $0.5 \%$.

\section{Statistical Analysis}

Viability and hatchability. The number of viable embryos on E16 (approximately $24 \mathrm{~h}$ postinjection) and the number of hatchlings were analyzed using $\chi^{2}$ analyses.

Blood vessel diameter. The apparent blood vessel diameters obtained during and after infusions were expressed and analyzed as percents of their individual baseline values. A two-factor repeated measures ANOVA and factorial ANOVAs for each of the four times after infusions were started, followed by preplanned contrasts were used for group comparisons, where appropriate. Based on previous studies (Mendoza-Baumgart et al, 2004; Schrott et al, 2002; Zhang et al, 1998), showing the vasoconstrictive effect of cocaine upon the chicks' extraembryonic vasculature, a unidirectional Dunnett's test was used as the preplanned contrast to compare blood vessel diameters of each treated group against the control group. Because of the possibility that the baseline diameters were partially influenced by constitutive synthase activity and nitric oxide production, we also compared vessel diameters in the $\mathrm{L}-\mathrm{NAME}+\mathrm{NaCl}$ group with other groups using the protected least significant difference (PLSD) test.

Nitric oxide synthase activity. Citrulline formation, expressed as pmol/100 mg brain, was analyzed as a measure of synthase activity. One-factor ANOVA followed by the Dunnett's test were used for statistical comparisons. We hypothesized an enhanced effect of cocaine upon blood vessel diameters because we used a synthase inhibitor (ie L-NAME). However, absent previous experimental evidence as to L-NAME's capacity to inhibit the enzyme, at the dose injected, a two-tailed contrast was used.

\section{RESULTS}

\section{Viability and Hatchability (Toxicity)}

An overall $\chi^{2}$ analysis found a significant effect of treatment upon E16 viability $\left(\chi_{3}^{2}=31.52, p<0.0001\right)$. Pretreatment 
Table I Viability and Hatchability

\begin{tabular}{lcc}
\hline $\begin{array}{l}\text { EI5 } \\
\text { treatment }\end{array}$ & $\begin{array}{c}\text { Number } \\
\text { viable/injected (\%) }\end{array}$ & $\begin{array}{c}\text { Number } \\
\text { hatched/injected (\%) }\end{array}$ \\
\hline $\mathrm{NaCl}+\mathrm{NaCl}$ & $34 / 35(97)$ & $33 / 35(94)$ \\
$\mathrm{LNAME}+\mathrm{NaCl}$ & $32 / 35(91)$ & $32 / 35(91)$ \\
$\mathrm{NaCl}+\mathrm{COC}$ & $25 / 35(71)^{+}$ & $23 / 35(66)^{+}$ \\
$\mathrm{LNAME}+\mathrm{COC}$ & $16 / 35(46)^{*}$ & $14 / 35(40)^{*}$ \\
\hline
\end{tabular}

${ }^{+}$A significant decrease in viability and hatchability in the $\mathrm{NaCl}+$ cocaine group (pretreated eggs) compared to the $\mathrm{NaCl}+\mathrm{NaCl}$ group, $p<0.005$.

*A significant decrease in viability and hatchability compared to all other groups when pretreated with LNAME followed by cocaine, $p<0.03$, or better.

with L-NAME followed by cocaine caused a significant decrease $(54 \%)$ in viability compared with cocaine $(29 \%)$ alone $\left(\chi_{1}^{2}=4.77, p<0.03\right)$. There was also an overall significant effect of treatment upon hatchability $\left(\chi_{3}^{2}=34.24, p<0.0001\right)$. Pretreatment with L-NAME followed by cocaine did not substantially reduce viability after E16, measured as hatchability on E20-22. Of the 34 viable embryos in the $\mathrm{NaCl}+\mathrm{NaCl}$ group on $\mathrm{E} 16,33$ eventually hatched. The remaining groups likewise were little affected after E16 (Table 1).

\section{Blood Vessel Diameter}

Baseline blood vessel diameters of the four treatment groups, when quite variable, were nevertheless not significantly different from one another. The mean absolute value for baseline diameters was $250 \mu \mathrm{m}$, ranging in size from 182 to $319 \mu \mathrm{m}$. Examples of images of the blood vessels before and after exposure to the vasoconstrictive action of salicylate plus cocaine at a time when eggs pretreated with $\mathrm{NaCl}$, followed by cocaine, did not yet show a vasoconstrictive effect of cocaine are shown elsewhere (MendozaBaumgart et al, 2004).

Repeated-measures ANOVA showed a significant main effect of treatment $(\mathrm{F} 3,28=19.24 ; p<0.001)$ and a repeated measures effect (F 3,84=13.77; $p<0.001)$. There was also a significant treatment by repeated measures interaction (F 9,84=11.59; $p<0.001$ ). Blood vessel diameters, relative to their respective baseline diameters, varied between 99.4 and $101.1 \%$ for the $\mathrm{NaCl}+\mathrm{NaCl}$ group, with an average of $100 \%$ for the four times after initiating infusions. The L$\mathrm{NAME}+\mathrm{NaCl}$-treated group showed a slight and transient but significant $6 \%$ reduction in vessel diameter compared to $\mathrm{NaCl}+\mathrm{NaCl}-$ and $\mathrm{NaCl}+$ cocaine-treated groups observed at 5 and $10 \mathrm{~min}$ into the cocaine infusion. The vessel diameters from the $\mathrm{NaCl}+$ cocaine-treated group, which were not significantly affected at 5 and $10 \mathrm{~min}$, took $15 \mathrm{~min}$ of cocaine infusion to cause a $9 \%$ reduction in diameter (ie vasoconstriction), which was significant compared with the $\mathrm{NaCl}+\mathrm{NaCl}$-treated group at this time, as well as at $5 \mathrm{~min}$ postinfusion. Pretreatment with L-NAME sensitized the vasculature to the vasoconstrictive effect of cocaine, causing a significant reduction (15\%) in vascular size immediately (ie within $5 \mathrm{~min}$ ), showing progressively greater vasoconstriction over the $20 \mathrm{~min}$ recording period, with an even greater $24 \%$ decrease in diameter at this time. Because

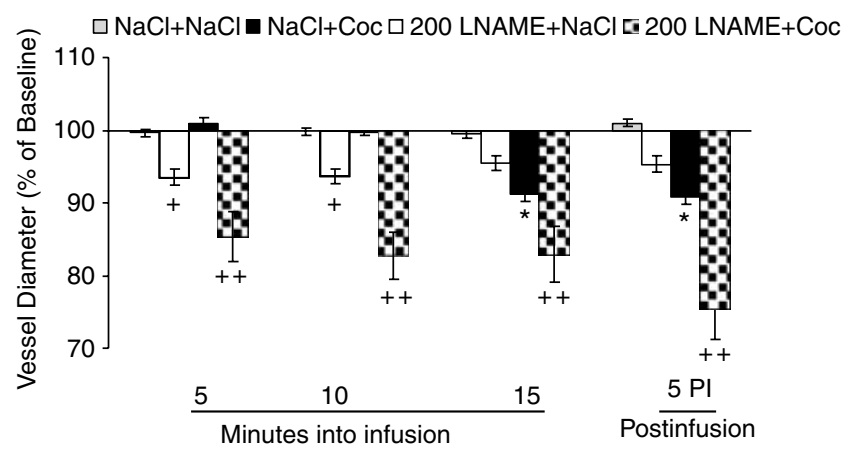

Figure 2 Blood vessel diameter. ${ }^{+}$A significantly decreased (BV) diameter in the L-NAME $+\mathrm{NaCl}$-treated group compared to the $\mathrm{NaCl}+$ $\mathrm{NaCl}$ - and $\mathrm{NaCl}+$ cocaine-treated groups 5 and 10 min into the infusion. *A significantly decreased (BV) diameter in the $\mathrm{NaCl}+$ cocaine-treated group after at least 15 min into the cocaine infusion. ${ }^{+}{ }^{+} \mathrm{A}$ significantly decreased (BV) diameter in the L-NAME + cocaine-treated group as soon as $5 \mathrm{~min}$ into the cocaine infusion when compared to all other groups.

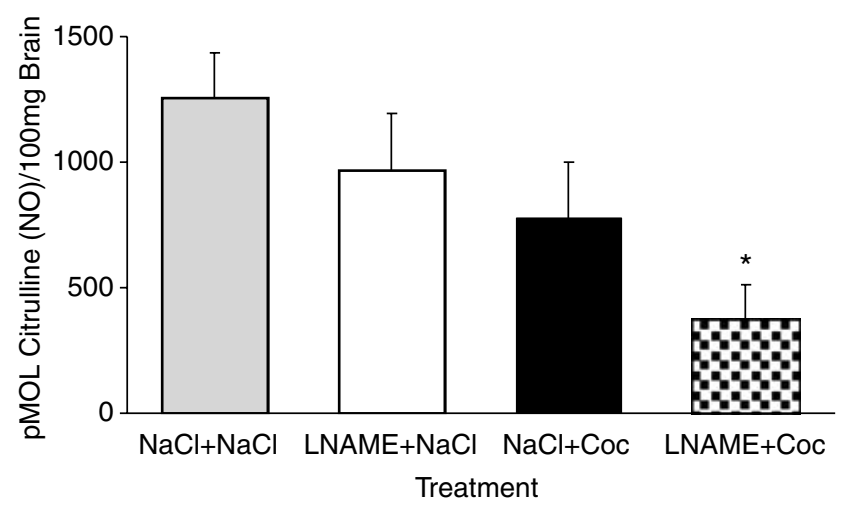

Figure 3 Citrulline formation. *A significantly decreased concentration of citrulline from enzymatic conversion of arginine in the L-NAME + cocaine-treated group, indicative of reduced nitric oxide synthase (NOS) activity; $p<0.02$. Brains were taken from embryos after a dose of cocaine comparable to an infusion dose of $22.5-45 \mathrm{mg}$ cocaine $/ \mathrm{kg}$ egg.

cocaine by itself caused a significant reduction in diameters at 15 and $5 \mathrm{~min}$ after the infusion was terminated, we took the liberty of comparing the diameters of both cocaine groups at these times with the use of the PLSD test. The outcomes indicated that the $17 \%$ reduction in vessel diameter in the L-NAME + cocaine group was significantly greater than the $9 \%$ reduction in the $\mathrm{NaCl}+$ cocaine group at $15 \mathrm{~min}$. Furthermore, $5 \mathrm{~min}$ after the infusion (ie postinfusion), the $\mathrm{NaCl}+$ cocaine group's vessel diameters remained at $91 \%$ of baseline, whereas the vessel diameters in the L-NAME + cocaine group was reduced to almost $25 \%$; likewise to a significant degree (Figure 2).

\section{Nitric Oxide Synthase Activity}

Only the brains from the L-NAME + cocaine-treated group showed a significant decrease of $70 \%$ in ${ }^{3} \mathrm{H}$-citrulline (ie nitric oxide) formation, when compared with the $\mathrm{NaCl}+$ $\mathrm{NaCl}$-treated group (Figure 3). The smaller reductions in enzyme activity in brains from the L-NAME $+\mathrm{NaCl}$ and $\mathrm{NaCl}+$ cocaine groups were not statistically reliable at the time we harvested brains, which was the experimental equivalent to doses and times when we saw enhanced 
vasoconstriction of extraembryonic vessels in eggs pretreated with L-NAME and infused with cocaine.

\section{DISCUSSION}

The slight (6\%) transient (ie 5 and $10 \mathrm{~min}$ ) but significant decrease in vessel diameter caused by injection of L-NAME suggests that nitric oxide may be constitutively produced by the endothelial cells for the maintenance of normal vascular tone and integrity (Nakamura et al, 2004; Wang et al, 2004; White et al, 2004). The lack of, or reduced nitric oxide production may then have been compensated for by other vasodilatory mechanisms, such as prostacyclin production (Bobadilla et al, 2005; Harrison and Cai, 2003). Although it has been reported that the lack of nitric oxide can decrease the biosynthesis of prostacyclin (Sautebin and Di Rosa, 1994), the dose of L-NAME we used may not have been sufficient enough to cause a substantial decrease in prostanoid synthesis, which could explain the return of vessel diameter sizes to normal, in the L-NAME $+\mathrm{NaCl}$ group, by $15 \mathrm{~min}$ into the infusion.

Cocaine by itself caused significant vasoconstriction compared to controls (ie $\mathrm{NaCl}+\mathrm{NaCl}$ ) and the L-NAME + $\mathrm{NaCl}$ group, but not until $15 \mathrm{~min}$ into the infusion and we have previously reported this vasoactive property of cocaine in this model (Mendoza-Baumgart et al, 2004; Schrott et al, 2002; Zhang et al, 1998). In addition, cocaine's vasoconstrictor action has been known for decades. It has been used as an experimental tool to block reuptake of released norepinehrine (NE) or effects of NE or other drugs that are put into isolated organ baths or injected into experimental animals (Zimmerman and Gisslen, 1968; Allen et al, 1965; Marsh and Van Liere, 1950). When pretreated with L-NAME, there was an enhancement of the vasoconstriction (ie the blood vessel diameters decreased significantly as soon as 5 min into the infusion, the earliest time taken for analyses). This synergistic vasoconstrictive effect of the combination of L-NAME + cocaine may be owing to the inability of the blood vessel to mount a compensatory vasodilation/ relaxation in response to the vasoactive effect of cocaine and is possibly secondary to the lack of, or reduced nitric oxide, which has been reported to modulate or enhance production of a prostanoid vasodilator, prostacyclin (Sautebin and Di Rosa, 1994). This effect of L-NAME in combination with cocaine upon the extraembryonic vasculature is similar to our previous study with salicylate in combination with cocaine, which resulted in an increase in brain inducible nitric oxide synthase mRNA concentration. We postulated that the increased synthase mRNA might be owing to a compensatory response to a decrease in prostacyclin and/or nitric oxide production caused by salicylate + cocaine. These experiments were undertaken to test that hypothesis more directly. The significant decrease in synthase activity caused only by the combination of LNAME + cocaine in the present study supports our hypothesis alluded to above. These developmental insults may have caused toxic and lethal effects on the developing embryo, leading to the greater decrease in both viability and hatchability demonstrated in the first experiment.

Cocaine using pregnant women presenting to a physician with symptoms of headache, abdominal pain, blurred vision, and increased blood pressure may be misdiagnosed as suffering from pre-eclampsia (Towers et al, 1993) and been given aspirin as part of their treatment. Moreover, aspirin, or more potent antiplatelet aggregation agents, has been suggested as a prophylactic treatment of cocaine abusers at risk for ischemic strokes, or with cerebral perfusion deficits, but the risk of gastrointestinal bleeding was a concern (Kosten et al, 2003, 2004). However, cocaine abuse is also associated with various hemorrhagic cerebrovascular accidents (Boco and Macdonald, 2004; Howington et al, 2003) and cocaine abusers experiencing headache caused by vasoconstriction and/or a CVA may self-medicate with more than one $325 \mathrm{mg}$ dose of aspirin (Wagener et al, 1994), which has typically been used in hospital-based diagnostic or treatment studies. We have reported that salicylate, the major metabolite of aspirin, caused a strikingly similar enhanced toxicity we report with L-NAME when used in combination with cocaine (MendozaBaumgart et al, 2004). This toxic interactive effect of cocaine upon a developing organism or in adult cocaine abusers, when used with various substances, is the basis for this study.

\section{ACKNOWLEDGEMENTS}

This work was supported in part by US Public Health Service Grants R37 DAO4979; T32 DAO7097 and a grant-inaid from the Minnesota Medical Foundation (3200-922-02).

\section{REFERENCES}

Akoka S, Descamps P, Genberg C, Franconi F, Arbeille B, Laurini R et al (1999). Cerebral MRI on fetuses submitted to repeated cocaine administration during the gestation: an ovine model. Obstet Gynecol Reprod Biol 85: 185-190.

Allen GD, Damon D, Tolas AG (1965). The effectiveness of drugs used for vasoconstriction of the nasal mucous membrane. Oral Surg Oral Med Oral Pathol 19: 599-603.

Amin AR, Vyas P, Attur M, Leszczynska-Piziak J, Patel IR, Weissmann $G$ et al (1995). The mode of action of aspirin-like drugs: effect on inducible nitric oxide synthase. Proc Natl Acad Sci USA 92: 7926-7930.

Bobadilla LRA, Perez-Alvarez V, Bracho Valdez I, Lopez-Sanchez P (2005). Effect of pregnancy on the roles of nitric oxide and prostaglandin in 5-hydroxytryptamine-induced contractions in rat thoracic and abdominal aorta. Clin Exp Pharmacol Physiol 32: 202-209.

Boco T, Macdonald RL (2004). Absence of acute cerebral vasoconstriction after cocaine-associated subarachnoid hemorrhage. Neurocrit Care 1: 449-454.

Bredt DS, Snyder SH (1990). Isolation of nitric oxide synthetase, a calmodulin-requiring enzyme. Proc Natl Acad Sci USA 87: 682-685.

Castelli MC, Venturini L, Sparber SB (2001). Cocaine and salicylate: documentation of hydroxyl radical formation in hearts and brains of 18-day-old chick embryos and unexpected interactive toxicity. Psychopharmacology 156: 23-31.

Frank DA, McCarten KM, Robson CD, Mirochnick M, Cabral H, Park H et al (1999). Level of in utero cocaine exposure and neonatal ultrasound findings. Pediatrics 104: 1101-1105.

Harrison DG, Cai H (2003). Endothelial control of vasomotion and nitric oxide production. Cardiol Clin 21: 289-302.

Howington JU, Kutz SC, Wilding GE, Awasthi D (2003). Cocaine use as a predictor of outcome in aneurysmal subarachnoid hemorrhage. J Neurosurg 99: 271-275. 
Ignarro LJ (2002). Nitric oxide as a unique signaling molecule in the vascular system: a historical overview. J Physiol Pharmacol 53: 503-514.

Kapur RP, Shaw CM, Shepard TH (1991). Brain hemorrhages in cocaine-exposed human fetuses. Teratology 44: 11-18.

Kosten TR, Gottschalk PC, Tucker K, Rinder CS, Dey HM, Rinder HM (2003). Aspirin or amiloride for cerebral perfusion defects in cocaine dependence. Drug Alcohol Depend 71: 187-194.

Kosten TR, Tucker K, Gottschalk PC, Rinder CS, Rinder HM (2004). Platelet abnormalities associated with cerebral perfusion defects in cocaine dependence. Biol Psychiatry 55: 91-97.

Levine SR, Brust FC, Futrell N, Brass LM, Blake D, Fayad P et al (1991). A comparative study of the cerebrovascular complications of cocaine: alkaloidal versus hydrochloride: a review. Neurology 41: 1173-1177.

Marsh DF, Van Liere EJ (1950). Effect of cocaine and ephedrine on the vasoconstriction produced by acute oxygen lack. Arch Int Pharmacodyn Ther 81: 207-210.

Mendoza-Baumgart MI, Pravetoni M, Sparber SB (2004). Vasoconstriction caused by cocaine is enhanced by sodium salicylate: is inducible nitric oxide synthase mRNA related? Neuropsychopharmacology 29: 1294-1300.

Nakamura T, Vollmar B, Menger MD, Inui K, Wada H, Schafers HJ (2004). Heme oxygenase does not contribute to control of basal vascular tone in isolated blood-perfused rat lung. J Heart Lung Transplant 23: 599-605.

Plessinger MA, Woods JR (1993). Maternal, placental and fetal pathophysiology of cocaine exposure during pregnancy. Clin Obstet Gynecol 36: 267-277.

Ryu YS, Lee JH, Seok JH, Hong JH, Lee YS, Lim JH et al (2000). Acetaminophen inhibits iNOS gene expression in RAW 264.7 macrophages: differential regulation of NF- $\kappa \mathrm{B}$ by acetaminophen and salicylates. Biochem Biophys Res Commun 272: 758-764.

Sautebin L, Di Rosa M (1994). Nitric oxide modulates prostacyclin biosynthesis in the lung of endotoxin-treated rats. Eur $J$ Pharmacol 262: 193-196.

Schrott LM, Baumgart MI, Zhang X, Sparber SB (2002). Prenatal opiate withdrawal activates the chick embryo hypothalamic pituitary-adrenal axis and dilates vitelline blood vessels via serotonin (2) receptors. J Pharmacol Exp Ther 303: 257-264.

Schrott LM, Sparber SB (2001). Embryonic 'binge' cocaine exposure alters neural-immune and neural-endocrine interac- tions in young chickens: involvement of serotonin receptors. Brain Res Dev Brain Res 130: 99-107.

Shimokawa H, Flavahan NA, Lorenz RR, Vanhoutte PM (1988). Prostacyclin releases endothelium-derived relaxing factor and potentiates its action in coronary arteries of the pig. J Pharmacol 95: 1197-1203.

Towers CV, Pircon RA, Nageotte MP, Porto M, Garite TJ (1993). Cocaine intoxication presenting as pre-eclampsia and eclampsia. Obstet Gynecol 81: 545-547.

Vane JR, Botting RM (1998). Anti-inflammatory drugs and their mechanism of action. Inflamm Res 47: S78-S87.

Venturini L, Sparber SB (2001). Salicylate and cocaine: interactive toxicity during chicken mid-embryogenesis. Free Radical Biol Med 30: 198-207.

Vorhees CV, Reed TM, Acuff-Smith KD, Schilling MA, Capon GD, Fisher E et al (1995). Long term learning deficits and changes in unlearned behaviors following in utero exposure to multiple daily doses of cocaine during different exposure periods and maternal plasma concentrations. Neurotoxicol Teratol 17: 253-264.

Wagener RE, Linder MW, Valdes Jr R (1994). Decreased signal in Emit assays of drugs of abuse in urine after ingestion of aspirin: potential for false-negative results. Clin Chem 40: 608-612.

Wang Y, Gu Y, Zhang Y, Lewis DF (2004). Evidence of endothelial dysfunction in preeclampsia: decreased endothelial nitric oxide synthase expression is associated with increased cell permeability in endothelial cells from preeclampsia. Am J Obstet Gynecol 190: 817-824.

White CR, Parks DA, Patel RP, Shelton J, Tarpey MM, Freeman BA et al (2004). L-Arginine inhibits xanthine oxidase-dependent endothelial dysfunction in hypercholesterolemia. FEBS Lett 561: 94-98.

Young SL, Vosper HJ, Phillips SA (1992). Cocaine: its effects on maternal and child health. Pharmacotherapy 12: 2-17.

Zhang X, Schrott LM, Sparber SB (1998). Evidence for a serotoninmediated effect of cocaine causing vasoconstriction and herniated umbilici in chicken embryos. Pharmacol Biochem Behav 59: 585-593.

Zimmerman BG, Gisslen J (1968). Pattern of renal vasoconstriction and transmitter release during sympathetic stimulation in presence of angiotensin and cocaine. J Pharmacol Exp Ther 163: 320-329. 